\title{
Digressões sobre a educação e o ensino de história no século XXI
}

Ernesta Zamboni*

RESUMO

Neste texto refletimos a respeito das concepções sobre o ensino de história existentes durante o século XX e projetamos a sua dimensão para o limiar do século XXI. Foram focalizado os objetivos da História e Educação como campo do conhecimento. Nestas reflexões pontuamos as inovações ocorridas nos campos das tecnologias e suas conseqüências para a vida do homem. Fundamentam as nossas reflexões os conceitos de identidade e consciência histórica.

Palavras-chave: ensino de história, identidade, consciência histórica, mudanças valores

0 presente é o momento instantâneo, nesta armadilha temporal temos dois tempos o passado o que passou e o futuro aquilo que virá. Cabe-nos, como historiadores usar a nossa inventividade para ler respostas indiretas naquilo que ficou para trás, isto é, no passado. 0 passado presente e o futuro constituem um continum (HOBSBAWN, 1998, p.50).

Ao receber o convite para participar deste encontro, cuja temática é refletir sobre a formação e o papel do professor para este milênio, escolhi pensar sobre o que poderá representar o conhecimento histórico para as novas gerações. A educação no século XXI é um desafio e tem, como característica, uma complexidade decorrente da multiplicidade de mudanças e transformações ocorridas, principalmente na segunda metade do século passado.

Presenciamos no século XX uma grande revolução tecnológica. Singularmente cito as formas de comunicação que reduziram de maneira significativa o tempo para realizá-la e permitiram uma intensidade e uma

* Professora Doutora FE/UNICAMP. 
qualidade no seu processamento jamais imaginadas. Basta para isso lembrar os meios digitais, a informática e particularmente a Internet. 0 resultado mais visível de tudo isso é aquilo que passou a se denominar de globalização. A intensificação da comunicação de massa induz as mais rápidas mudanças comportamentais. A dimensão do tempo modificou a noção do "minuto" para representar uma medida de tempo considerável, tanto para as comunicações como para os sistemas de produção.

0 avanço tecnológico tem afetado a vida das populações ribeirinhas, rurais, enfim daquelas populações que, no passado recente, viviam isoladas dos grandes centros. Elas estão premidas na luta pela sobrevivência e pelo tempo da produção. Elas estão sendo expulsas de seus locais de vivência pela ocupação desordenada dos espaços, obrigando-as a imigrarem principalmente para os grandes centros urbanos onde as suas condições de sobrevivência se agravam. Este fenômeno tem provocado graves desequilíbrios sociais, com profundas perdas de identidades e raízes.

As pesquisas na área médica avançam auxiliadas por novas investigações cientificas e tecnológicas e aprimoram o conhecimento do corpo humano e as possibilidades de cura das doenças, entretanto, a medicina, com os recursos da engenharia genética e de outros campos das investigações que atuam diretamente com o ser humano, enreda em sérias questões éticas e religiosas. Cito, como exemplo, desse aspecto, as observações de McLaren sobre os genomas humanos e a clonagem.

[...] a ciência eugênica que esta surgindo como uma tendência evolucionista em que os "genes" convertem-se em "ouro verde", que impulsionará o futuro da economia mundial. A pressão para que as reservas de genes tenham a proteção das patentes presenciou tentativas clandestinas, por parte do governo norte-americano, de "privatizar o corpo humano", obtendo patentes para as células dos índios guaymi do Panamá e das populações das ilhas Salomão, Papua Nova Guinée da Índia e fazendo com que as corporações norte-americanas possam beneficiar-se do controle mundial sobre a clonagem da vida humana (MCLAREN, 2000, p. 121).

0 cinema tem explorado a vertente da ficção cientifica, como o filme Matrix, onde o principal personagem se movimenta em um tempo extremamente 
rápido. 0 perfil dos novos super-homens é outro. Nessas realidades virtuais, a noção de tempo a elas associada chega a adquirir uma dimensão superior à velocidade da luz.

Como podemos observar, o conceito e o valor do ser humano se modificaram, deslocaram-se do seu interior para o exterior e socialmente são reconhecidos pelo que consomem. A visibilidade social é permeada pelo que ostenta e não por valores morais e práticas de cidadania.. 0 marketing usa de todos os recursos que possam estimular o consumo. Algumas frases, que se tornaram celebres, na década de 60, por conterem um apelo à liberdade, à paz e por expressarem a indignação, como Faça amor, não faça a guerra"; "A liberdade é uma calça velha, azul, desbotada, Corra para bem longe da sua casa", pela ambivalência de sentido, foram usadas como propaganda, divulgação para venda das calças jeans, e de tênis e a prática do joggins (SEVCENKO, 2001, p. 86).

As propostas educacionais, tanto as relativas às políticas públicas como aquelas referentes à escola, não acompanharam os avanços tecnológicos, científicos e as mudanças sócio culturais que aconteceram. Em consequiência, milhares de crianças e adultos estão fora da escola e de qualquer outro projeto educacional. 0 princípio da escola democrática e universal não se realizou, embora a construção da escola e o conceito de educação que nortearam a organização das escolas data do final do século XVIII estivesse articulada aos ideais liberais, no quais a educação foi tomada como um direito universal. Afirma Boto que, o propósito iluminista.

a pedagogia propunha-se, desde então, como um campo de saber cuja meta seria o rompimento dos pilares da tradição, para firmar conceitos teóricos e procedimentos metodológicos que se apresentassem universalmente válidos e cientificamente comprovados para preparar o caminho das gerações vindouras (2003, p.379).

Nesse período, á escola primária para Condorcet deveria prever "o desenvolvimento das primeiras idéias morais e das regras de conduta que delas derivam, finalmente, os princípios de ordem social que possam colocar-se ao alcance da inteligência infantil" (BOT0, 2003, p.747). "A educação escolar deveria dirigirse a busca da verdade e para isso seria voltada para o aprendizado da história... e das 
ciências morais (BOT0, 2003, p.749). É ainda Condorcet que afirma a necessidade de se organizarem festas nacionais consagradas à memória da revolução. É a introdução das festas cívicas na escola.

Embora constituísse uma das premissas, o direito universal à educação ou seja a oferta a todas as crianças das mesmas oportunidades, não passou de um sonho. Ter um projeto único e homogêneo de educação significou, na prática, excluir, consolidar distinções e criar ambigüidades. A educação proposta atendeu à nascente burguesia e trabalhou na formação de uma identidade nacional e na formação do estado nacional moderno. Neste sentido, a Educação e a disciplina História tiveram um caráter enciclopédico, moral, marcado pela idéia de progresso e deveriam dar visibilidade à nação. A idéia de progresso estava assentada na relação passado, presente e futuro. A educação com estas características marcou o século XX, adquiriu novas feições e novas identidades, mas a escola continuou não acessível a todos.

Quais os indícios que vamos procurar no século XX e o que orientará a nossa inventividade para pensar quais escolas e quais conhecimentos históricos escolares serão necessários à população no século XXI?

Há uma multiplicidade de indícios e recorro às imagens produzidas em um caleidoscópio, em que a cada movimento novas cores e formas aparecem. Escolher uma delas significa deixar tantas outras de lado. Meu enfoque será parcial e limitado, acrescido pela subjetividade do meu olhar. As produções, as vivências e as experiências sobre educação são tão diversas e múltiplas que não conseguimos ter uma visão completa de todos os seus ângulos. Também, temos dificuldade em dimensionar as nossas reflexões em uma período de longa duração. Portanto, as minhas reflexões estão sujeitas aos limites estabelecidos pelo tempo/espaço e pela complexidade existente no dimensionamento do conhecimento histórico e cultural.

0 meu olhar se dirigiu às propostas feitas em encontros internacionais, na década de 1990, cuja temática foi a educação. Em 1990 ocorreu a conferência Mundial em Jorrítien, na Tailândia, cuja decisão foi centrada na criação de metas de universalização da educação básica. No Brasil, esta meta que foi trabalhada, como se pode ver nos dados apresentados por Castro "a taxa líquida de matrícula passou de 86\%, em 1991, para $96 \%$ em 1999. Isso representa, em números absolutos, a inclusão no sistema de cerca de 6,8 
milhões de crianças, das quais cerca de 91\% em escolas públicas" (2001, p. 324). Em 1995 na Conferência Internacional da Mulher, realizada em Pequim, as questões educacionais centralizaram o fórum das decisões. Em 1998, na reunião da Cúpula das Américas ocorrida em Santiago do Chile, o tema central foi "A educação como a chave para o progresso", cujas metas foram assegurar a educação básica para $100 \%$ das crianças, garantir que $75 \%$ dos jovens tenham acesso à educação secundária e "educação continuada" a população em geral. Como se pode observar, a educação foi considerada como estratégia necessária e política para a promoção do desenvolvimento humano, fortalecimento da cidadania econsolidação da democracia em vários continentes, principalmente na África, Ásia e América.

Para Luis Rigal, professor da Universidade Nacional de Jujuy, Argentina, (2000, p.172), as preocupações que orientam suas reflexões sobre educação no século XXI são: a ética, a política e as questões epistemológicas. Como preocupação ética, situa a necessidade de se definir que tipo de homem se quer formar, que tipo de sociedade e de estilo de vida que se deseja. Como preocupação política, relaciona a educação com o estabelecimento das relações de poder, tanto no interior das instituições escolares como no interior das estruturas sociais; a escola centraliza as idéias de justiça e igualdade para a formação de sujeitos livres. Como preocupação epistemológica, o conhecimento constitui o fundamento para compreensão da realidade e do pensamento crítico e analítico necessários a ações transformadoras da sociedade.

Outro investigador, Francisco Imbernón, da Universidade de BarcelonaEspanha, aponta para a educação no século a necessidade de as instituições escolares estarem preocupadas com os seguintes desafios:

a. 0 direito à diferença e à recusa a uma educação excludente,

b. a educação ambiental como mecanismo fundamental de preservação e melhoramento da natureza,

c. a educação política dos cidadãos como uma educação para a democracia, d. a reformulação da função dos professores,

e. consideração da escola como espaço físico educativo (IMBERNÓN, 2000, p.82). 


\section{Ensino de História}

Estão presentes nas reflexões, valores como cidadania (no sentido mais amplo), ética, identidade e conhecimento. São valores que se aproximam das idéias de Condorcet : A educação escolar deveria dirigir-se à busca da verdade e para isso seria voltada para o aprendizado da bistória.. e das ciências morais. Relacionando esses princípios com a proposta de estudar 0 Conhecimento Histórico Escolar, centralizarei as minhas reflexões na procura de princípios que caracterizem o conhecimento histórico escolar na dimensão dos estudos sobre identidades e no significado da manutenção das tradições.

0 discurso liberal e a laicizacão da sociedade foram os princípios que marcaram, no século XIX, o ensino de História. Fundamentado no positivismo, o ensino enfatizou a História dos fatos políticos e estes foram os marcos da periodização histórica. 0 Estado foi valorizado como gestor e controlador da Nação e seus dirigentes, os sujeitos históricos. Como disciplina escolar, a História foi o lugar privilegiado, como preconizava Condorcet, para se trabalhar a moral e a ética como valores universais, constituindo desta forma a pedagogia da Nação. A história torna-se o sinônimo da nação e da civilização (ZAMBONI, 1998, p.10).

No período republicano esta concepção de história é aprofundada. Nadai afirma:

as representações, no ensino de história, que procuravam expressar as idéias de nação e de cidadão estavam embasadas na identidade comum de seus variados grupos étnicos e classes sociais constitutivos da nacionalidade brasileira. 0 fio condutor do processo histórico centralizou-se,assim, no colonizador português e, depois no imigrante europeu e nas contribuições paritárias de africanos e indígenas (NADAI, 1993, p.143-146).

Durante o Estado Novo, o ensino da história pautava-se pela formação da identidade nacional e buscava envolver a sociedade e os estudantes em grandes festas em atividades esportivas e em campanhas cívicas. A composição dos livros didáticos divulgava princípios ideológicos que sustentavam o governo. A proposta para o ensino de história estava centrado no estudo e na afirmação 
de uma Unidade Nacional para o Brasil, sem reconhecer as diferenças regionais, étnicas, religiosas e atribuir à toda população a mesma historia. Capelato afirma que:

0 ensino de historia tinha a função de criar nos adolescentes e jovens estudantes uma paixão e um saber, um sentimento e o conhecimento acerca das tradições do país. Ao recuperar tradições nacionais, elevaria o sentimento dos indivíduos para uma percepção do todo nacional (1998, p. 221).

Com a reforma curricular de 1941, proposta do governo de Getúlio Vargas, a questão nacional continuou sendo o fio norteador como o fora no século XIX. 0 viés nacionalista é reforçado, na década de 50, com a introdução do estudo de História da América. Os princípios que nortearam a seleção dos conteúdos de História foram o nacionalismo, americanismo e a civilização. A introdução do ensino da História da América foi no sentido de reforçar a identidade americana e distanciar-se da Europa.

0 estado e as elites e os intelectuais brasileiros, ao se voltarem para si mesmos em torno da construção da nação, utilizam também como ponto de referência os demais povos americanos, que servirão como um espelho para fazer revelar a sua própria imagem (DIAS, 1997).

Os temas da História da América no currículo, como colonização, processo de independência e cultura dos povos pré-colombianos, estão presentes nos livros didáticos quando relacionados à História do Brasil.

Guy de Hollanda estuda o período de mudanças temáticas no ensino de História e, que em 1956, publica um livro sobre metodologia e prática do ensino tendo como referência para análise dos programas de história e dos livros didáticos. Neste trabalho, ele chama a atenção para os objetivos do ensino de História que são o conbecimentos essencial do passado bumano e uma aprendizagem elementar da crítica bistórica (HOLLANDA, 1957, p.7). A finalidade do ensino de história é o estudo do passado e a aprendizagem está relacionada a uma metodologia facilitadora da aprendizagem e a uma postura crítica. 
A política desenvolvimentista de Juscelino Kubitscheck(1956-1961) provocou grandes mudanças políticas e sociais. Com o processo de industrialização, com o êxodo rural e com o crescimento desordenado das cidades, exige-se um novo tipo de trabalhador, uma nova concepção de cidade e conseqüentemente uma nova escola. No final dos anos 50 e durante os anos 60 , grupos de educadores sentiram a necessidade de propor uma renovação na escola, tanto no setor das escolas particulares como no das públicas. Foram criadas, principalmente nas regiões sudeste e sul, escolas experimentais centradas nos interesses dos alunos, nos estudos da família e da comunidade. Os temas sócio-políticos constituíram o centro das propostas curriculares e as discussões políticas daí decorrentes acabaram por conduzir ao fechamento de muitas escolas ou à mudança de currículo decorrente do ato institucional n. 5, também conhecido como A.I.5, no final de 1968.

Em plena ditadura militar, em 1971, foi aprovada uma nova Lei das Diretrizes e Bases da Educação, a 5692, que modificou o sistema fundamental de ensino criando três áreas interdependentes: Comunicação e Expressão, Estudos Sociais e Artes e Comunicação. 0 período de duração passou de 4 para 8 anos. A Historia e a Geografia, como disciplinas autônomas, desapareceram do currículo e foram reorganizadas como Estudos Sociais. 0 objetivo máximo foi a formação da cidadania, isto é, como o cidadão interage com a sua comunidade.

Na década de 80, no final da ditadura militar, quando já se prenunciava a redemocratização, foi necessário que se pensasse em um novo currículo para as escolas. Os estudos sobre a aprendizagem e as investigações referentes a procedimentos teórico-metodológicos adotados nos estudos historiográficos e os novos objetos propostos pela Historia Nova mostravam o conservadorismo existente nos currículos anteriores e a necessidade de se pensar em uma outra escola, com outras propostas educacionais. Alertavam, também, para a importância da participação ativa de todos os professores nos processos educacionais e não aceitavam a separação entre a pesquisa e docência. Temas políticos existentes nos currículos são abandonados e temas culturais e sociais ocupam um espaço de destaque na dinâmica do ensino de História.

$\mathrm{Na}$ década de 90 , pensadores como Chartier, Darton, Guinzburg, Benjamim, Castoriades, Thompson e outros nacionais como Bresciani, Capelato, De Decca, Lenharo, Contier e tantos outros, deram sustentação à 
propostas de ensino que usava a literatura como uma fonte documental e necessária na construção de um cenário de época, isto é, como uma nova linguagem para o ensino de História. Outra proposta muito presente nos currículos foi os estudos referentes à História Local através da recuperação das tradições e memórias das pessoas e dos lugares. Os atuais estudos de História Local buscam a recuperação das identidades locais, das coletivas, a identificação e aceitação das diferenças, das aproximações e dos distanciamentos.

Galzerani (1998), ao justificar a importância da recuperação das memórias e das Histórias Locais, se reporta ao filósofo Walter Benjamin:

[...] no momento atual, em que se aceleram os processos culturais globalizantes, as tradições locais tendem a desaparecer. As singularidades culturais locais, dos indivíduos desapareceram em prol do global, do novo, da rapidez da dimensão temporal, do encurtamento das distancias criado por todos os meios de comunicação. Os homens têm perdido a sua dimensão temporal e cultural, para assumir um comportamento homogeneizador, que afeta as suas sensibilidades, os seus gostos, os seus traços culturais.

Como já foi exposto, a perspectiva da educação para o século XXI não se desprende das diretrizes do P.C.N., Plano Nacional da Educação, proposto em 1997, que expressa as suas preocupações com as novas tecnologias, com a ecologia, com a conservação ambiental e com a luta para se alcançar o estado pleno de cidadania. Portanto, ao pensar a respeito dos pressupostos para o ensino de história para o atual século, não se pode desprender do enraizamento do seu passado tanto individual como social; tanto local como universal.

\section{As identidades na contemporaneidade}

A memória, a tradição e as experiências vividas estão presentes em nossas trajetórias de sujeitos conscientes e, quando nos referimos à educação, estes elementos se fazem necessários. Essa relação consciente entre a educação e a história nos permite, sem sermos visionários, perceber situações passíveis de acontecer. Nestas reflexões é substantiva a compreensão que temos da história, do significado das tradições, das memórias, das diferentes culturas e do momento 
presente. Nesse sentido memória e identidade (considerada como pluralidade cultural e não meramente ideológica) são redimensionadas e não distanciadas dos valores imbutidos na luta pela cidadania. A memória deverá ser tomada como rememoração na resubjetivação dos sentidos culturais e para que isso aconteça é necessário que haja a consciência das experiências presentes, como afirma Diehl (2002 p.113).

Os processos identitários conseguem apenas resubjetivar os elementos culturais que fazem sentido para o seu grupo social e nunca para a sociedade como um todo e isto significa o compartilhar das identidades. "Caso contrario a identidade passa a ser ideologia, facilmente vinculada a concepção de cultura nacional" (DIEHL, 2002, p.115).

A compreensão da identidade é importante para as pessoas perceberem os elos, mesmo imaginários, que as mantém unidas. Por exemplo, o relembrar das torturas vividas por prisioneiros políticos, nos cárceres e nos campos de concentração e das discriminações sociais, étnicas, religiosas, culturais e políticas, sofridas por determinados grupos, tem maior significação para aqueles que vivem como memória ou que os conhecem as tradições familiares e culturais, mas nunca com significação para a sociedade como um todo. Grupos sociais ou pessoas que tenham sofrido a perda ou a fragmentação de seus traços identitários fazem parte de um fenômeno que sempre ocorreu via processos de violência. Como exemplo, o processo de dominação sofrido pelas populações africanas e ameríndias, no período da colonização da América, foi feito através da imposição de um idioma e de uma religião que os impossibilitava de se comunicarem entre si, de reverenciarem os seus deuses e de fazerem os seus rituais religiosos. Este tipo de dominação afetou profundamente os traços identitários destes grupos, fragmentou os seus códigos de comunicação e provocou a perda de seus valores intrínsecos. Em parte, devido a este fenômeno, é que descendentes de diferentes etnias, como a dos negros, indígenas, europeus e asiáticos, têm feito um esforço, muito acentuado, para recuperar e estudar suas tradições, seus rituais e seus usos e costumes. Ao lado deste esforço, tais etnias têm criado arquivos e museus para conservarem suas memórias

Dado a atual complexidade da dinâmica da vida social, em que os traços identitários se afirmam, fortalecem-se ou enfraquecem-se os estudos referentes a este tema tendem a obter relevância para se compreender os fatos sociais que 
envolvem os diferentes grupos sociais (MOREIRA e MACEDO, 2002, p.11). Esta perspectiva ultrapassa as diretrizes propostas pelos PCNs: 1997:

0 ensino e a aprendizagem de historia estão voltados, inicialmente, para atividades em que os alunos possam compreender as semelhanças e as diferenças, as permanências e as transformações no modo de vida social, cultural e econômico de sua localidade, no presente e no passado, mediante a leitura de diferentes obras humanas (BRASIL/MEC/SEF 1997, p.49 apud FONSECA, 2003, p.154).

Estas nossas preocupações com o estudo e a formação das identidades nos encaminham para refletir sobre as afirmações de Manique e Proença (1994), historiadoras portuguesas, também preocupadas com este fenômeno

[...] na aldeia global em que vivemos, os meios de comunicação põem-nos em permanente contacto com múltiplos testemunhos dos dramas da humanidade e, constantemente também, os adolescentes são confrontados com atitudes, costumes e formas de vida para os quais não dispõem de qualquer referente valido. Essa situação, agravada pela progressiva desestruturação familiar (outra fonte importante de memória), contribui certamente para os problemas de identidade dos jovens nas nossas escolas.

Uma identidade constrói-se a partir do conhecimento da forma como os grupos sociais de pertença viveram e se organizaram no passado, mas também da verificação da forma como se estruturam para fazer face aos problemas do presente, tendo uma componente que aponta par ao futuro, pelo modo como este se prepara por meio da fixação dos objectivos comuns (apud FONSECA, 2003, p.156).

Para se compreender os movimentos identitários e orientar os nossos trabalhos de docência, há necessidade de se auscultarem os silêncios para se perceber os significados culturais que a identidade assume como cultura. Portanto, o estudo da identidade requer cuidados especiais para se compreenderem a ética e a moralidade dos processos, tanto da destruição como da constituição das identidades. Tais reflexões não se coadunam com um ensino de história fundamentado em uma idéia de construção de uma única identidade, para todos, através do viés nacionalista, nem tão pouco, com 
uma história sócio-cultural que fundamenta a identidade nas características culturais e sociais da população dos alunos, da sua família e da cidade e na diversidade cultural. Este procedimento favorece as discriminações, os preconceitos, as intolerâncias e a polarização entre identidades. A nossa preocupação está em refletir sobre as identidades e reconhecer as diferenças e as semelhanças nos traços históricos, étnicos, culturais e sociais no processo de construir e reconstruir as identidades nacionais fundada em uma visão de história que nos conduz às reflexões sobre cidadania.

Entre as múltiplas preocupações presentes nos diálogos dos docentes que se dedicam ao Ensino Fundamental e Médio, estão as diversidades sócio-culturais existentes entre os discentes e a natureza e escolha do conteúdo a ser desenvolvido na sala de aula. Entretanto, na atualidade, as preocupações referentes ao conhecimento são controversas, em parte pela quantidade e diversidade da produção historiográfica acumulada em todo o século XX, principalmente em suas nas últimas décadas, e em parte pelos novos objetos, novas abordagens e novos problemas apontados pelos historiadores da História Nova francesa como Pierre Nora, Jacques Le Goff, Georges Duby, Michel Certeau e outros, cuja influência foi marcante no ensino fundamental e médio. Não podemos ignorar as inovações, advindas através dos novos meios de comunicação, e as mutações valorativas que a sociedade tem sofrido com a globalização.

Em sintese, o que pode ser caracterizado como as nossas identidades é o fato de pertencermos a um grupo, a uma comunidade que nos sustenta afetivamente e culturalmente, e como consciência bistórica, o conhecimento de que vivemos em sociedades em constantes mudanças, com estreitas relações entre as temporalidades, passado, presente e futuro razões porque torna-se importante que pensemos nas possíveis diretrizes que poderão orientar o ensino de historia e a própria educação.

Sem dúvida, tais diretrizes poderão ser múltiplas e plurais.

A História tem funções fundamentais para a sociedade, como afirma Quintanar "es el conocimento que por definición entrega el fundamento, la base de sustentación, al hombre de nuestro tiempo y de hecho, de todos los tiempos" (2000, p. 295). Ainda, segundo Boto, a educação “... é a ação exercida pelas gerações adultas sobre as gerações que não se encontram ainda preparados para a vida social; tem por objeto suscitar e desenvolver, na criança, certo 
número de estados físicos, intelectuais e morais, reclamados pela sociedade política no seu conjunto e pelo meio especial a que a criança, particularmente, se destine" (p.380, 2003) Estas afirmações reforçam a ação da educação no processo de formação das gerações mais novas e a história dá à juventude as raízes e a sustentação dos homens na atualidade.

Como pesquisadora na área do ensino de história, acredito que devemos refletir a respeito dos vínculos existentes entre a educcção e a história e estabelecer relações entre os seus princípios epistemológicos. Politicamente, privar povos e populações da educação e do conhecimento histórico é certamente impedi-los de crescimento e desenvolvimento além de contribuir para que se tornem submissos, o que levará comprometer seriamente à formação de uma consciência histórica. É importante, entretanto, fazer-se a ressalva de que o fato de se ensinar história não significa que se está formando no aluno a consciência histórica. Inúmeras vezes o professor não tem pleno conhecimento da concep̧̧ão de história que transmite aos seus alunos e não consegue estabelecer as relações existentes entre as várias temporalidades, com o predomínio, muitas vezes de um ensino histórico sem referenciais temporais.

A aprendizagem do conhecimento histórico poderá ser feita de diversas maneiras: pela leitura, pela observação e pela reflexão, em diferentes lugares como museus, arquivos, cinemas e teatro, em manifestações e com diferentes linguagens. A aplicação de diferentes metodologias significa criar possibilidades de formulações e questionamentos para se vivenciar o conhecimento histórico, que levará à formação das identidades, do sentimento de pertencimento e da consciência histórica, isto é, do pensar historicamente.

Afirma Machado Pais (1999, p.1) que:

sem consciência histórica sobre o passado não perceberíamos quem somos. Esta dimensão identitaria - quem somos? - emerge no terreno de memórias partilhadas. Por isso, o sentimento de identidade - entendida no sentido de imagem de si, para si e para os outros - aparece associado a consciência histórica, forma de nos sentirmos em outros que nos são próximos, outros que antecipam a nossa existência que, por sua vez, antecipara a de outros. Ao assegurar um sentimento de continuidade no tempo e na memória (e memória do tempo), a consciência histórica contribui, deste modo, para a afirmação da identidade - 
individual e coletiva. É sabido que História não tem sentido independentemente daquele que os indivíduos the dão. Por isso, o estudo das formas de consciência historia é uma forma de conhecimento que nos permite descobrir como os indivíduos vivem com os "fantasmas" do passado e, simultaneamente, os utilizam como forma de conhecimento (apud SCHMIDT, 2002, p.195).

Retomar algumas afirmações feitas anteriormente, a na reunião da Cupula das Américas, em 1998, ocorrida em Santiago do Chile, o tema central foi "A educação como a chave para o progresso". o conceito aplicado à palavra progresso foi considerado como estratégia necessária e política para a promoção do desenvolvimento humano. De certo modo, as diretrizes propostas pelos PCNs em 1997, orientava que

o ensino e a aprendizagem de história estariam voltados, inicialmente, para atividades em que os alunos pudessem compreender as semelhanças e as diferenças, as permanências e as transformações no modo de vida social, cultural e econômico de sua localidade, no presente e no passado, mediante a leitura de diferentes obras humanas (BRASIL/MEC/SEF 1997).

Diante dos fatos, cabe-me perguntar: que tipo de educação os órgãos internacionais almejam para a humanidade e como se situa o ensino de história na atualidade?

Em minhas reflexões, recorro à teoria da história com o objetivo de me auxiliar na formação da nossa capacidade de reflexão, tanto nas ações que envolvem o trabalho docente como 0 da investigação. A reflexão certamente amplia o nosso poder de argumentação e de julgamento e colabora com a formação o sujeito cognoscente que se reconhecer nos objetos. nas ações do seu cotidiano. sem contudo deixar de lado a cultura histórica. ${ }^{1}$

1 Cultura histórica significa a articulação prática da consciência historia em uma determinada sociedade. A rede desta articulação se estende desde o ensino de história a nível escolar até aos rituais comemorativos oficiais, dos manuais didáticos até os museus e monumento e muitos outros lugares da memória coletiva. Entendido desta maneira, a cultura histórica integra funções de lembrar como o ensino, a diversão, a critica, a ilustração e outras funções que incluem tantos os elementos cognitivos como os imaginários, emocionais (GARCIA, 1998,p.291). 


\section{Referências}

BOT0, C. Acivilização escolar como projeto político e pedagógico da modernidade: cultura em classes, por escrito. In: CADERNO CEDES - ARTE \& (MANHAS DOS PROJETOS POLÍTICOS E PEDAGÓGICOS. v.23, n.61- Campinas, CEDES, 2003.

Na Revolução Francesa, os princípios democráticos da escola pública, laica e gratuita: o relatório de Condorcet. In: Revista Educação \& Sociedade. Educação: de direito de cidadania a mercadoria. Novas Leituras sobre o público e o privado mercantil. n. 24, v.84, Campinas, CEDES, 2003.

CAPELATO, M. H. R. Multidões em Cena. Campinas, Papirus, 1998.

CASTRO, M. H. G. 0 Brasil e os compromissos internacionais na área de educação. In: Conferência Nacional de Educação, Cultura e Desporto ; coletânea de textos da $1^{\text {a. }}$. Conferência Nacional de Educação, Cultura e Desporto - Brasília: Câmara dos Deputados, Coordenação de publicações, 2001.

DIAS, M. de F. S. Invenção da América na cultura escolar. Tese de doutoramento, defendida na Faculdade de Educação da UNICAMP, em 1997.

DIEHL, A. A. Cultura bistoriográfica: memória, identidade e representação. Bauru, São Paulo. EDUSC, 2002.

FONSECA, S. G. Didática e Prática de Ensino de História. Campinas, São Paulo: Papirus, 2003.

GALZERANI, M. C. B. O significado da bistoria local para o ensino face a aceleração da globalização cultural. Texto mimeo. Campinas, 1998.

GARCÍA, V. R. Aprendizaje Histórico : algunas consideraciones y propuestas didácticas desde una óptica alemana. In: SILLER, J. P.; GARCÍA, V. R. (org.) Identidad en el Imaginário Nacional. Concepciones y Experiências em la Ensenanza de la Historia, Instituto de Ciencias Sociales y Humanidades, BUA, Puebla, México 1998.

HOBSBAWM, E. Sobre História. Trad. Cid Knipel Moreira - São Paulo: Cia. das Letras, 1998.

HOLLANDA, G. Um quarto de século de programas e compêndios de bistoria para o Ensino Secundário brasileiro 1931-1956. Rio de Janeiro. INEP - Ministerio de Educação e Cultura, 1957, p.7. 
IMBERNÓN, F. (org.) Amplitude e profundidade do olhar : a educação ontem, hoje e amanha. In A educação no século XXI - os desafios do futuro imediato. Artmed Editora, Porto Alegre, 2000.

MCLAREN, P. Pedagogia revolucionaria em tempos pós-revolucionários: repensar a economia política da educação crítica. In: IMBERNÓN, F. (org.) A educação no século $X X I$ - os desafios do futuro imediato. Artmed Editora, Porto Alegre, 2000.

MOREIRA, A. F. B.; MACEDO, E. F. de. Currículo, identidade e diferença. In, Currículo, Praticas Pedagógicas e Identidades. Porto Editorq, Porto, Portugal, 2002

NADAI, E. 0 ensino de história no Brasil: trajetória e perspectiva. In: Revista Brasileira de Historia-Memória, História e Historiografia. Dossiê ensino de história n. 25/26. São Paulo. ANPUH/Marco Zero, setembro 92/agosto 93, p. 143-162.

QUINTANAR, A. S. Identidade y consciência en la ensenanza dela Historia. In: SILLER, J. P.; GARCÍA, V. R. (org.) Identidad en el Imaginário Nacional. Concepciones y Experiências em la Ensenanza de la Historia, Instítuto de Ciencias Sociales y Humanidades, BUA, Puebla, México 1998.

RIGAL, L. A escola critico-democratica: uma matéria pendente no limiar do século XXI. In: IMBERNÓN, F. (org.) A educação no século XXI - os desafios do futuro imediato. Artmed Editora, Porto Alegre.

RUSEN, J. Razão Histórica : Teoria da bistória: os fundamentos da ciência bistórica.. Trad. de Estevão Rezende Martins - Brasilia: Editora Universidade de Brasilia, 2001. . El desarrollo de la competencia narrativa en el aprendizaje historico. Una Hipótesis ontogenética relativa a la conciencia moral.Revista Propuesta Educativa, Facultad Latinoamericana de Ciencias Sociales, Buenos Aires, ano 4, n.7, p.27-36, out. 1992.

SCHMIDT, M. A. Jovens brasileiros e europeus: identidade, cultura e ensino de história (1998-2000). Perspectiva. Florianópolis, v.20, n. Especial, p. 183-208. jul/dez.2002.

SEVCENKO, N. A corrida para o século XXI. No lop da montanha- russa. Coordenação de Laura de Mello e Souza e Lilia Moritz Schwarcz. São Paulo. Cia. das Letras, 2001.

ZAMBONI, E. Orientações Metodológicas presentes no currículo e na docência do ensino de história do Brasil. In:Agora, v. 4, n.12 (jan./dez.1998) - Santa Cruz do Sul. Edit. da UNISC, 1999. 


\section{Digression about Education an Theaching of History twenty first century}

\section{ABSTRACT}

This article is about the conceptions of the teaching of History during the twenticth century and its projection towards the threshold of the twenty-first century. The objectives of History and Education as a branch of knowledge are focused here. I also point ou the great innovations occurred in the technology and its consequences for the mankind. The concepts of identity and the historic conscience are the basis of our reflections.

Key works: theaching of history, identity, historic conscience, changes, value. 